\title{
WHY CAN WHOLE BODY VIBRATION (WBV) CAUSE REDNESS ON VOLUNTEERS? THE EFFECT OF MECHANICAL VIBRATION AND ANXIETY ON PERIPHERAL BLOOD FLOW
}

\author{
Juliana Gonçalves Dornela and Maria Lúcia Machado Duarte* \\ PPGMEC/UFMG: Post-Graduation Program in Mechanical Eng., Universidade Federal de \\ Minas Gerais; GRAVI ${ }_{\mathrm{HB}}$ : Group of Acoustics and Vibration in Human Beings, BRAZIL \\ mlduarte@dedalus.lcc.ufmg.br
}

\section{Introduction}

Mechanical vibrations are physical stimuli that are present in various occupational or even leisure environments, as well as in the daily lives of the population in general. Although the majority of the studies investigate the damaging effects associated to vibration, nothing much is found on the effects of vibration on the peripheral circulation, being that the main objective of this article.

The peripheral circulation can be considered as one whose flow is directed to the muscular system (muscles) and the integumentary system (epidermis and dermis) ${ }^{1}$. The substance responsible to promote the vasodilatation in blood flow is nitric oxide (NO). The NO plays a role in modeling the diameter and vascular resistance of the blood vessels by its ability to relax their sleek muscles ${ }^{5}$.

In an experiment conducted by the Group of Acoustics and Vibration in Human Beings - GRAVI $\mathrm{HB}_{\mathrm{B}} / \mathrm{UFMG}$, to investigate the effects of whole body vibration (WBV) on human hearing, it was observed that one of the volunteers apparently anxious by the stimulation, presented in the neck and upper limbs redness in some points. However, soon after the stimulus (at $5 \mathrm{~Hz}, 2.45 \mathrm{~m} / \mathrm{s}^{2}$ in the Z-axis vibration, during approximately 8 minutes), these signs disappeared. Faced with this fact, this article aims at discussing about an updated review on the subject in order to understand what would be the effect of mechanical vibration and anxiety/stress in the peripheral blood flow so to justify the results found in the GRAVI $\mathrm{HB}_{\mathrm{B}} / \mathrm{UFMG}$ research.

\section{Methods}

Papers were reviewed ${ }^{2}$, without limitation of initial time until 2010, which related anxiety and/or mechanical vibration (both local and whole body) with their effects on the peripheral blood flow, in order to justify the results found during the GRAVI $\mathrm{HB}_{\mathrm{HB}} / \mathrm{UFG}$ research. The survey was conducted in libraries and databases such as Medline, Lilacs, BIREME, Pubmed, Wiley Interscience and Science Direct.

\section{Results and Discussions}

In total, only 10 studies were found on the effects of mechanical vibration on peripheral blood flow ${ }^{2}$. All these studies found that vibration leads to increased shear stress on the walls of blood vessels. This increase in the mechanical forces has an effect on the DNA. That is because the nitric oxide (NO) is synthesized from the information originating in the DNA of the cells which transcribes this information to the mRNA for the production of nitric oxide (NO), sending it to the tissues of blood vessels (endothelium) where the enzymes nitric oxides (NOs) are present and receive it for the synthesis of NO. Consequently, there is vasodilatation, causing increase in the blood flow, making the skin redness turns visible. 
Only seven studies used humans as sample ${ }^{2}$. Moreover, it was observed a great variation between the studies regarding both the types of vibrations used (3 used local vibration and 7 whole body vibration), as well as in relation to both the frequency ranged (0.23 to $2000 \mathrm{~Hz}$ ) and vibration amplitudes (displacement from 2 to $6 \mathrm{~mm}$ and/or acceleration from 2.22 to $46 \mathrm{~m} / \mathrm{s}^{2}$ ) employed. There was no standard on how the vibration information was presented, making the interpretation and comparison of the findings more difficult, as in some cases, not all the necessary information was even reported.

One study ${ }^{3}$ in dogs and 2 studies $^{4,6}$ in humans used similar amplitude and frequency to that used in the experimental study by $\mathrm{GRAVI}_{\mathrm{HB}} / \mathrm{UFMG}$, arriving to the same conclusions, corroborating to the hypothesis of the study. Therefore, although the region investigated was different, similar conclusion may be drawn.

About the influence of anxiety on peripheral blood flow, 7 studies were found ${ }^{2}$ and all these studies corroborate to the occurrence of increased blood flow in the forearm of humans when they are subjected to situations of anxiety / mental or emotional stress.

It was not found any study about the combined factors (vibration/anxiety).

\section{Conclusions}

There are few studies in the literature reporting about the effects of the vibrations on peripheral blood flow. Nevertheless, from the studies found, it may be concluded that in the study by $\mathrm{GRAVI}_{\mathrm{HB}} / \mathrm{UFMG}$ an increase in the shear forces on the blood vessels walls had caused peripheral vasodilatation and redness in certain parts of the upper limbs and cervical region of the volunteer. Furthermore, the anxiety, as seen in the literature, also causes peripheral vasodilatation and contributed to the appearance of such signals in the volunteer. However, no study was found about the combined effect, vibration/anxiety, being that a suggestion for future work. Moreover, one important point is the urgent need to standardize the information relative to the vibration parameters, with all the relevant information reported, in order to easier the comparison and interpretation of the findings.

\section{Acknowledgment}

The authors would like to thanks the financial support given to this work by FAPEMIG and CNPq.

\section{References}

1. Berne, R.M. and Levy M.N. (2000). Principles of Physiology, Third Edition. Mosby,Inc., St. Louis, MO. 256-64 apud Lohman III, E.B., Petrofsky, J.S., Maloney-Hinds,C., Betts-Schwab, H. and Thorpe D. (2007). The effect of whole body vibration on lower extremity skin blood flow in normal subjects. Med Sci Monit.13(2), pp 71-76,

2. Dornela, J.G. and Duarte, M.L.M. (2010). Effects of Mechanical Vibration and Anxiety on Peripheral Blood Circulation: Review of Literature to Explain Redness Caused by the Presence of Whole Body Vibration (WBV). Internal Report. GRAVI $\mathrm{HB}_{\mathrm{B}} / \mathrm{UFMG}$.

3. Hood, W.B. and Higgins, L.S., (1965). Circulatory and respiratory effects of whole-body vibration in anesthetized dogs. Appl Physiol 20, pp 1157-1162.

4. Lythgo, N., Eser,P., Groot,P. and Galea, M. (2009). Whole-body vibration dosage alters leg blood flow. Clin Physiol Funct Imaging 29, pp 53-59.

5. Wong, G.K.T. and Marsden, P.A. (1996). Nitric oxide synthases: regulation in disease. Nefrol Dial Transplant 11, 215-20.

6. Zhang, Q., Ericson, K.. and Styf, J. (2003). Blood flow in the tibialis anterior muscle by photoplethysmography during foot-transmitted vibration. Eur J Appl Physiol 90, pp 464-469. 